\title{
HIMALAYAN FISHERIES AND AQUACULTURE IN THE ERA OF CLIMATE CHANGE : SOME INSIGHT TO ENDEAVOR OUR FUTURE RESEARCH
}

\author{
A. K. SINGH \\ ICAR-National Bureau of Fish Genetic Resources, Lucknow (U.P.)
}

\begin{abstract}
Fish is known as one of the most efficient converters of feed into high quality food and its carbon footprint is lower compared to any other animal production systems. Through fisheries and aquaculture there is substantial contribution to the income and food security in the Himalayan region. So far technological and institutional support ensured combined production of fish through fisheries and aquaculture in the Himalayan region. Now climate change on fish and fisheries will result into changes in biological and abiotic components and anthropogenic changes. The vulnerability of Himalayan fisheries and aquaculture to climate change and anthropogenic stresses bring up potential responses to work out mitigation requirements. Ecosystem-based adaptation (EbA) is an increasingly popular strategy being adopted for addressing the linked challenges of climate change and poverty in Himalayan ecosystem, where dependence on natural resources for lives and livelihoods is high. Some of the climate-driven shifts and changes are discussed for endeavoring scientific solutions and sustaining the Himalayan fisheries and aquaculture. Scientific data on genetic diversity, ecological processes such as primary productivity, population recovery from disturbances, interspecific competition, community structure, and fluxes of energy and nutrients are important areas for managing our resources effectively. It is proposed that knowledge and understanding of the dynamics of the food, water, and energy and the possible areas of trade-offs and synergies should be broadened through support integrated modeling research for sustainable development.
\end{abstract}

Key words : Climate, Species distribution, Sex ratio, Gonadal disruption, Molecular biomarkers.

\section{INTRODUCTION}

The Himalaya is one of the world's most sensitive hotspots to global climate change, with impacts manifesting at a particularly rapid rate. Climate change in the Himalayas, home of many sacred landscapes, and the source of eight largest rivers of Asia, is likely to impact the well-being of $20 \%$ of humanity (Xu et al.,2009). A situation that is predicted to intensify in coming years, with dire and far-reaching impacts on food, water and energy security, as well as biodiversity and species loss. Himalayan system therefore, needs to rigorously work in this $2,500 \mathrm{~km}$ long, highly inaccessible, pristine and fragile environment that constitutes water tower to one of the most densely populated country of world (Immerzeel et al., 2010). The impacts of climate change in the Himalayas are real where melting glaciers, erratic and unpredictable weather conditions, changing rainfall patterns, and increasing temperatures are impacting on the people, wildlife and aquatic ecosystems of the region.

Aquatic systems in the mountain region that sustain fisheries and aquaculture are undergoing significant changes as a result of global warming and anthropocene changes where human activity has been the dominant influence on climate and the environment suggested that these changes will be accentuated in the future. Today humans move more soil, rock and sediment each year than all natural processes. It is apparent that there is an increased pressure on all livelihoods and food supplies, including fisheries and aquaculture sector. The impacts of climate change on fish and fisheries will result from changes in biological and abiotic components and anthropogenic changes. Changes in water temperature, water levels, extreme climatic events, diseases, and climate-driven shifts in predator and prey abundances will all impact fisheries. Fishes are poikilothermic and their metabolic and reproductive physiological processes and disease resistance is temperature dependent. Increased water temperature allows fish to increase their metabolism, which in turn increases their oxygen demand.combined.

\section{RESULTS AND DISCUSSION}

The vulnerability of Himalayan fisheries and aquaculture to climate change and anthropogenic stresses bring up potential responses to adapt and such changes and mitigation requirements are presented in this paper. Ecosystem-based adaptation ( $\mathrm{EbA})$ is an increasingly popular strategy being adopted for addressing the linked challenges of climate change and poverty in Himalayan ecosystem, where dependence on natural resources for lives and livelihoods is high. Several changes are now perceived and scientific data are now being generated. Some of such changes perceptible and the insight are presented here to endeavor into future course of research need in coldwater fisheries sector (Fig.1).

A. Species distributional, richness and phonological changes : Most ecological processes now show responses to anthropogenic climate change. In Himalayan freshwater ecosystems, species are changing genetically, physiologically, morphologically, and phenologically and are shifting their distributions, which affects food webs and results in new interactions. These distributional shifts of fishes are leading to new ecosystems and ecological communities that will affect ecosystem functions (Fig.2). Disruptions scale from the gene to 
the ecosystem have documented consequences for people, including unpredictable fisheries and crop yields, loss of genetic diversity in wild and increasing impacts of pests and diseases (Gretta,2017).

Wetlands in the form of lakes are now vanishing fast even the lakes existed on an altitude of 3000-6000 masl may alter its eco-biological functions. Kashmir valley lakes Dal and Wular in Jammu and Kashmir of India are being reduced in size through the process of eutrophication, explosive growth of aquatic plants and encroachment of agriculture into their margins. Catch composition of ichthyofana of different aquatic bodies are now changing. Schizothorax niger a lacustrine highly endemic fish species of J\&K is now available in Jhelum river in Kashmir. The morphomeristic measurements of the specimens having length of 75-374 $\mathrm{mm}$ and weighing 56-557 g captured from the Dal lake and the Jhelum river has shown high co-efficient of correlation $\left(\mathrm{R}^{2}\right)$ values ranging from 0.51-0.96 for Dal lake stocks and 0.51-0.85 for Jhelum stocks indicating that the characters were highly correlated to each other and also that there existed a homogeneity within the populations. The fecundity of the fish is now reduced with a mean value of 21981.60. Another important endemic fish species of J\&K is Schizothorax labiatus in the Jhelum river. The snow trout Species are undergoing evolutionary adaptation to temperature extremes, and climate change. The amount of habitat loss is positively related with the pooled endemic species richness (here is the case of species from different Schizothorax and Schizothoraichthys genus). There are apparent physiological adjustments and observable impacts on morphology, with many species shrinking in body size because large surface-to-volume ratios are generally favored under warmer conditions and species richness and distribution. Other morphological changes include hybridization. There is urgent need to take up a study on the distribution, biology and population of various species of Schizothorax and schizothoraichthys in the Himalayan region. Further, we have very limited information on Diptichus maculatus, which is available mainly in river Indus and its tributaries in Ladakh, and also in Chandra-Bhaga river in Lahaul and Spiti valley of Himachal Pradesh. Since there is only one species of this genus represented in Indian waters, we need to generate maximum scientific information on its ecology, biology, reproduction and distribution.

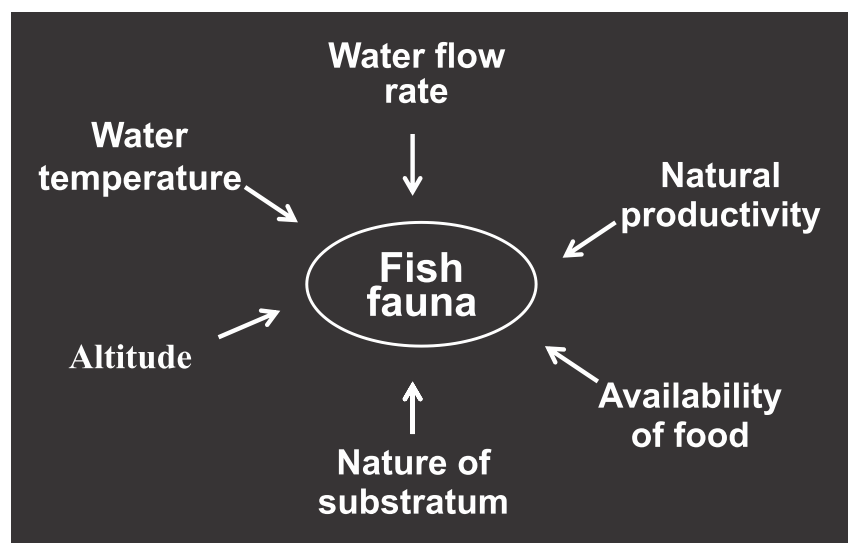

Fig. 1 Common factors influence fish fauna in Himalayan streams.
B. Shift in sex ratio, maturity and reproductive functions : Climate change has substantial impacts on species physiology that include changes in tolerances to temperature variations, shifts in sex ratios in species with temperaturedependent sex determination, and increased metabolic costs of living in a warmer world, gonadal disruptions and disturbed thermoregulation, and even migrations. Further it is argued that many hidden dynamics, such as genetic changes, are also taking place. Understanding shifts in ecological processes can guide human adaptation strategies towards shift from fisheries to aquaculture to reduce pressure on wild fish genetic resources. In addition to reducing greenhouse gases, climate action and policy must therefore focus equally on strategies that safeguard biodiversity and ecosystems.

In the Himalayan ecosystem, skewed sex ratio has been observed especially in Snow trout and mahseer fish species. Their likely response to the challenges associated with global climate change is in many ways dependent upon the effects of new environmental inputs on essential physiological processes. 'Plasticity 'and 'evolutionary changes 'are two primary mechanisms by which populations might alter phenotypes in response to environmental change (Akhtar et al., 2017). It is widely accepted that phenotypic plasticity is a characteristic of most living organisms and it can aid population persistence during periods of rapid environmental change. Temperature dependent sex determination is now reported and well understood in teleosts (Singh,2013). It would therefore, be important to understand the sex specific gene expression against environmental stress in mahseer and snow trout which would further be helpful in understanding the genetic factors contributing to the skewed sex ratio as well as the sex specific environmental resistance against environmental stress. Further, changed temperature and increased $\mathrm{CO}_{2}$ levels evidenced an anti-estrogenic effect i.e. VTG inhibition and cholinergic modulation, possibly due to a disturbance of brain ionic homeostasis which, in turn, impair neuro transmission and hormone synthesis. Hormones and enzymes that indicate environment-related stress on certain fish species can be harnessed as biomarkers to develop a computational model to predict changes in fish production and distribution in the coldwater region.

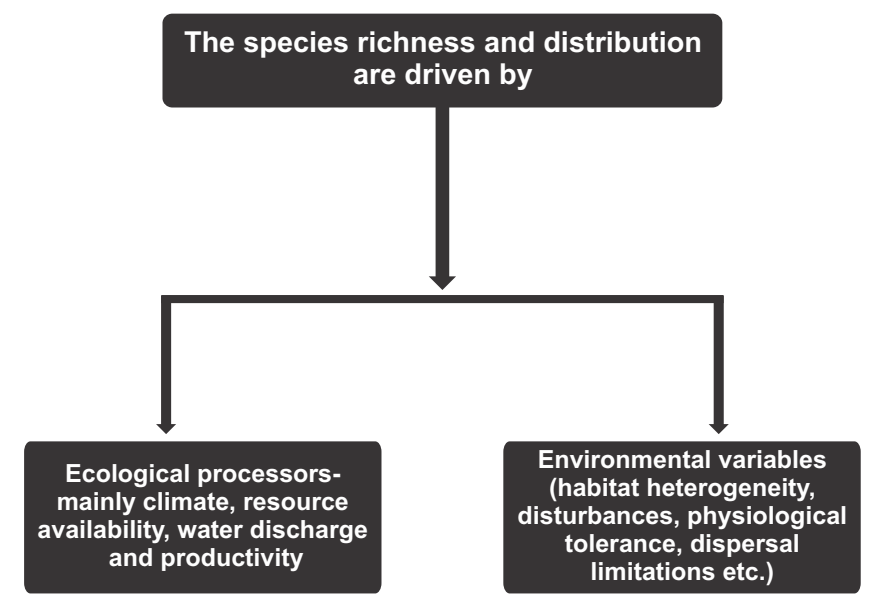

Fig. 2 Ichthyofaunal diversity and distributional pattern. 
C. Climate Change and Fish Invasions : Because of its pervasiveness and potential effect on fundamental biological processes, climate change will interact with other existing stressors to affect the distribution, spread, abundance, and impact of invasive fish species. Many native species will shift their geographic distributions, moving into areas where they were previously absent. There are all reasons to specify carefully what is meant by an invasive species. We define invasive species as those taxa that have been introduced recently and exert substantial negative impact on native biota, economic values, or human health. Therefore, we do not consider a native species that has expanded its range under climate change to be invasive unless it causes discernable damage (Hellmann et al., 2008 and Singh \& Lakra,2011). Invasive species with established populations, range change results from successful spread into new areas. Spread is likely to follow changes in temperature constraints that occur with warming or changes in hydrologic constraints as a result of altered precipitation patterns (Singh and Lakra,2011). Consequently, many exotic fish species such as common carp is full in several lakes and rivers in the Himalayan region. The potential for changes in temperature, precipitation, and eutrophication to affect invasive fish species management will necessitate coordinated responses at large spatial scales, new research, and more extensive monitoring. Climate change, is more subtle and long term, and resource managers will have a difficult time knowing when to start addressing it. It will take more research to understand how specific invasive species may behave under an altered climate and which new species will emerge as invasive.

D. Use of molecular biomarkers in the degrading aquatic environment : As we continue to battle against poor water conditions due to climatic variations, growing industrialization, eutrophication and pollution, monitoring becomes more important than ever. Aquatic organisms readily accumulate metals and organic contaminants, present in the water column, sediment or food (Singh et al.,2014 and Singh et al., 2017). Exposure to and toxic effects of contaminants can be measured in terms of the biochemical responses of the organism so-called molecular biomarkers. The applications, advantages and limitations of such diagnostic and prognostic tests are discussed. The hepatic biotransformation enzyme cytochrome P4501A in fish and other vertebrates is specifically induced by organic contaminants such as aromatic hydrocarbons, PCBs and dioxins, and is used as a biomarker of exposure to organic pollution. Its induction is involved in chemical carcino genesis via catalysis of the covalent binding of organic contaminants to DNA (DNA-adducts). CYP1Ainduction, measured as enzyme activity, enzyme amount, or mRNA, has been successively used in many field studies in fishes (Ariadna et al.,2019).

E. Adoption of Climate smart Aquaculture : Trout and other species of coldwater fish face an increasingly uncertain future in the streams and rivers due to the effects of global warming. Rising temperatures will likely impact these coldwater species of fish across the broad range of areas they inhabit. Trout and mahseer are especially vulnerable to global warming because of their dependence on clear, cold water. Culture of rainbow trout (Oncorhynchus mykiss) in the hill states has been considered as the promising species for mountain fisheries development in India. Today, farming of trout is being carried out on several fish farms in Kashmir, Himachal Pradesh, Uttarakhand, Arunachal Pradesh and Sikkim. The siting of these aquaculture facilities was based on the availability of water in required quantity and quality, i.e. from rheocrene springs and snow-melt/glacier-fed streams. The aquatic resources in hills are quite valuable for the development of aquaculture and fishery both for food, sport, recreation and employment but scientific management of these resources is necessary to achieve the objectives. In order to manage these ecosystems, it is necessary to take up appropriate strategic plans and action so that hill aquatic resources and aquaculture activities may contribute to fishery and aquaculture substantially in remote hilly regions on a sustainable basis. Further, knowledge and understanding of the dynamics of the food, water, and energy and the possible areas of trade-offs and synergies should be broadened through support integrated modeling research. This will help in developing climate resilient aquaculture models for sustainable development.

F. Suggested Adaptive Measures : Followings are some of the adaptive measures suggested to mitigate the impact of climate change :

1. Defining and mapping natural and potential fish-based resources in Himalayas for harnessing sustainable benefits.

2. To create Knowledge base on fish diversity and in relation to biological and physico-chemical parameters of natural systems those are critical for the usage and sustainability of Himalayan ecosystems.

3. Development of suitable technologies that contribute to capabilities for coping with stresses in mountain livelihood systems and mitigate loss of diversity in Himalayan aquatic ecosystems.

4. Introduction of improved fish varieties for mountain fisheries (carps, trouts, catfishes etc) assessed and validated for their contribution to resilience and improved livelihoods.

5. Identify collective action programmes that guarantee controlled management of natural resources.

6. Adoption of a conservation-by-use philosophy and better integration of agriculture, livestock, forestry, aquaculture and local processing to help diversify income sources and make mountain food systems more resilient to climate change.

G. Policy Issues : Some of the policy issues are presented here in the back drop of my previous publication (Singh,2019)

- "Policy for revival of imperiled species and its stock enhancement : Most stakeholders support endangered species protection, but the details of how different organizations, states, and the country achieve these protections is not yet clear. By providing a full and accurate science based picture, we can help ensuring future decisions that are made by looking at sound science and policy (George et al.,2009).

- "Environmental flow regulations : Environmental flow is 
a key factor to protect river ecological system, however, there is no regulatory mechanism developed so far. At last, a specialized legislative proposal is needed to be developed for protection of aquatic ecosystems and their environment in the Himalayas (Chen et al.,2013).
- Guidelines to resolve conflicts of stakeholders : Indirect wider socio-economic effects (e.g. fresh water use conflicts affect all food production systems, adaptation and mitigation strategies in other sectors will impact aquatic systems in general or fisheries and aquaculture directly.

\section{REFERENCES}

Akhtar, M. S.; Ciji, A.; Sarma, D.; Rajesh, M.; Kamalam, B. S.; Sharma, P. and Singh, A. K. (2017). Reproductive dysfunction in females of endangered golden mahseer (Tor putitora) in captivity. Animal Reproduction Science appeared online https://doi.org/10.1016/j. anireprosci.2017.05.004.

Ariadna, S.; Szczybelski, Martine J. van den Heuvel-Greve, Albert A. Koelmans and Nico W. van den Brink (2019). Biomarker responses and biotransformation capacity in Arctic and temperate benthic species exposed to polycyclic aromatic hydrocarbons. Science of The Total Environment. DOI : 10.1016/j.scitotenv.2019.01.034, 662,631-638.

Chen Changchun, Lachun Wang, Xuezhang Cao and Jie Song (2013). Environmental flows legislations and regulations in foreign countries and the enlightenment to China. Applied Mechanics and Materilas, pp. 295-298, 2181-2186. Online available since 2013/Feb/13at www.scientific.net.Trans Tech Publications Switzerland DOI 10.4028.www.scientific.net/AMM.295-298.2181.

George Anna L., Bernard R. Kuhajda, James D. Williams, Mark A. Cantrell, Patrick L. Rakes, and J. R. Shute (2009). Guidelines for Propagation and Translocation for Freshwater Fish Conservation. Fisheries, 34(11) : 529-545. www.fisheries.org.

Gretta, T. Pecl (2017). Biodiversity redistribution under climate change : Impacts on ecosystems and human well-being. Science, 201731 Vol. 355, Issue 6332, eaai9214 DOI : 10.1126/science.aai9214.

Hellmann, Jessica J.; James E. Byers, Britta G. Bierwagen and Jeffrey S. Dukes (2008). Five potential consequences of climate change for Invasive species. Conservation Biology, 22(3) : 534-543. https://doi.org/10.1111/j.1523-1739.2008.00951.X

Immerzeel, W. W.; Van Beek, L. P. H. and Bierkens, M. F. P. (2010). Climate change will affect the Asian water towers. Science, 328 : $1382-$ 1385 .

Singh, A. K. (2019). Coldwater Fisheries in India : Priorities, Policy, Institutional Support and Challenges. Advanced Agricultural Research and Technology Journal, $3: 2$

Singh, A. K.; Verma, R. and Jaiswal, Kamal (2017). Bisphenol-A and Hexachlorocyclohexane induced changes in gonadal sex hormones in an Indian major carp, Labeo rohita (Ham.,1822). International Journal of Zoological Investigations, 3(1): 58-71.

Singh, A. K.; Srivastava, Sharad, C.; Verma, Pankaj; Ansari, Abubakar and Verma, Ambrish (2014). Hazard assessment of metals in invasive fish species of the Yamuna river, India in relation to bioaccumulation factor and exposure concentration for human health implications. Environmental Monitoring and Assessment, 10.1007/s10661-014-3660-6.

Singh, A. K. (2013). Introduction of modern endocrine techniques for the production of monosex population of fishes. General and Comparative Endocrinology, 181 : 146-155.

Singh, A. K. and Lakra, W. S. (2011). Risk and benefit assessment of alien fish species of the aquaculture and aquarium trade into India. Reviews in Aquaculture, 3 : 3-18

Xu, J.; Grumbine, R.; Shrestha, A.; Eriksson, M. and Yang, X. (2009). The melting Himalayas : Cascading effects of climate change on water, biodiversity, and livelihoods. Conserv. Biol., 23 : 520-530. 